\title{
Estilos de Pensamento na Escolha da Especialidade Médica e Sua Correlação com as Políticas de Provimento para a Atenção Básica à Saúde - Um Estudo de Caso
}

\section{Thought Styles in the Choice of Medical Specialty and their Correlation with Primary Care Provision Policies - A Case Study}

Marcos Aurélio Maeyama ${ }^{I}$ Marco Aurélio da Ros ${ }^{I}$

\section{PALAVRAS-CHAVE}

- Educação Médica.

- Atenção Básica à Saúde.

- Sistema Único de Saúde.

- Residência Médica

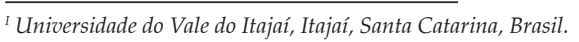

\section{RESUMO}

A publicação das Diretrizes Curriculares Nacionais para os cursos de Medicina, em 2001, iniciou um processo de mudança nos cursos de Medicina, buscando atender às necessidades do Sistema Único de Saúde no que diz respeito à formação para a atenção básica. Uma das maiores dificuldades encontradas para a consolidação da atenção básica reside na na carência de profissionais em quantidade e qualidade. Nesse contexto, o objetivo desta pesquisa, de cunho qualitativo, foi identificar os aspectos que envolvem a escolha da especialidade médica em alunos egressos da Universidade do Vale do Itajaí (Univali) que tiveram participação efetiva durante a graduação em projetos na atenção básica. A coleta de dados foi realizada por meio de entrevistas semiestruturadas, e a análise de dados foi executada por meio da categoria Estilo de Pensamento, desenvolvida por Ludwik Fleck. Os resultados demonstraram a hegemonia de um estilo de pensamento com características voltadas para a especialidade focal e com visão mercantil sobre a profissão, porém com visão ampliada para abordagem dos problemas, denominado, dessa forma, Estilo de Pensamento Flexneriano Ampliado. De modo contrahegemônico, também foi identificado um estilo de pensamento voltado à prática generalista integral, com caráter eminentemente público, aqui chamado de Estilo de Pensamento da Atenção Básica. A hegemonia do Estilo de Pensamento Flexneriano foi justificada especialmente pela força dos acoplamentos neoliberais, corroborados também pela estrutura curricular majoritariamente flexneriana. As complicações vivenciadas por alguns entrevistados no trabalho de atenção básica também foram consideradas impedimentos importantes que dificultam a consolidação do Estilo de Pensamento da Atenção Básica e, consequentemente, sua escolha como campo de trabalho. Os tráfegos intercoletivos também apresentaram importância no processo de escolha da especialidade médica, porém ainda hierarquizados pelos acoplamentos. Em que pesem estas escolhas, a aproximação com a atenção básica demonstrou ser bastante importante na construção da contra-hegemonia e na formação de matiz com visão ampliada do Estilo de Pensamento Flexneriano clássico, ambos importantes para a mudança do modelo de atenção. 


\section{KEYWORDS}

- Medical Education.

- Primary Health Care.

- Unified Health System.

- Medical Residency.

Recebido em: 27/10/17

Aceito em: 23/11/17

\section{ABSTRACT}

With the publication of the National Curriculum Guidelines for medical schools, in 2001, changes were implemented in medical courses with the aim of meeting the needs of the Unified Health System in terms of Primary Health Care training. One of the biggest difficulties found in the setting of Primary Health Care was that the staff was lacking both in numbers and quality of the professionals. In this context, the qualitative goal of this research was to identify the features surrounding the choice of medical specialty among graduates from UNIVALI who had effectively participated in Primary Health Care projects during their undergraduate studies. The data was collected by means of semi-structured interviews and the data analysis performed using the Thought Style category, developed by Ludwik Fleck. The results revealed the hegemony of a Thought Style with characteristics aimed at the focal expertise and with a market-oriented outlook on the profession, yet with an expanded view to addressing problem, and was therefore called the Extended Flexnerian Thought Style. In a counter-hegemonic way, another Thought Style was identified that focuses on comprehensive general practice, with an eminently public appeal, here entitled the Primary Health Care Thought Style. The hegemony of the Flexnerian Thought Style was especially justified by the force of neoliberal links, and supported by the predominantly Flexnerian curriculum structure. The complications experienced by some of the interviewees working in Primary Health Care were also considered major obstacles that hinder the consolidation of a Primary Health Care Thought Style and, consequently, the choice to work in that particular field. Inter-group movements was also show to be an important factor in the process of choosing a medical specialty, yet still under ordered according to the links. In spite of these choices, a closer approach to Primary Health Care proved to be very important in building the counter-hegemony forming the expanded view of the classic Flexnerian Thought Style, which are both important for changing the heath care model.

\section{INTRODUÇÃO}

O modelo biomédico no Brasil inicia sua grande hegemonia na década de 1960, sustentado pelo apoio e financiamento do governo militar para a construção de hospitais e compra de equipamentos, favorecendo a iniciativa privada ${ }^{1}$, e pela publicação em 1968 da Lei n 4.024, que estabeleceu as Diretrizes e Bases da Educação Nacional, que ordenava aos cursos de Medicina a adoção do currículo mínimo com base no modelo flexneriano de ensino².

Em contraposição ao modelo biomédico, inicia-se na década de 1970 o Movimento pela Reforma Sanitária Brasileira, defendendo uma atenção à saúde mais abrangente ${ }^{3}$.

O grande marco da Reforma Sanitária Brasileira ocorre em 1988, com a criação do Sistema Único de Saúde (SUS), que propunha a reorganização do sistema, considerando, entre outras questões, a universalidade e a integralidade da atenção ${ }^{4}$.

A Atenção Primária à Saúde (APS) foi o modelo proposto para responder a estas novas demandas constitucionais, e, com sua expansão, fica evidente o descompasso entre educação e atenção ${ }^{2}$.
A publicação das Diretrizes Curriculares Nacionais (DCN) para os cursos de Medicina, em 2001, como produto da iniciativa conjunta dos ministérios da Saúde e da Educação, representa a aproximação entre a atenção à saúde e a educação médica, tendo a APS como ponto de convergência ${ }^{5}$, pelo menos no que se refere ao plano legal.

As DCN impulsionaram inúmeros projetos de mudança, como o Programa de Incentivo a Mudanças Curriculares nos Cursos de Medicina (Promed), o Programa Nacional de Reorientação da Formação Profissional em Saúde (Pró-Saúde), o Programa de Educação pelo Trabalho para a Saúde (PET-Saúde), entre outros, dando ênfase ao componente da atenção básica e da formação integral, promovendo mudanças na educação médica no Brasil.

Porém, na prática, os gestores municipais não têm conseguido contratar médicos para a atenção básica, seja pela má distribuição, seja pela escolha dos profissionais por outra área de atuação e principalmente pela quantidade insuficiente de profissionais, comprovada pela proporção de 1,8 médicos por 
mil habitantes, bem abaixo de países como Argentina e Uruguai, cuja proporção apresenta, respectivamente, 3,2 e 3,7 médicos por mil habitantes ${ }^{6}$.

O curso de Medicina de uma universidade do Sul do Brasil participou do Pró-Saúde e PET-Saúde, e criou o projeto de extensão Sérgio Arouca, buscando responder às DCN, dando ênfase ao componente da atenção básica durante a formação.

Nesse contexto, o presente trabalho buscou identificar os estilos de pensamento presentes na escolha da especialidade médica de egressos que participaram ativamente de projetos que envolveram a atenção básica durante a graduação.

\section{METODOLOGIA}

Foi utilizada abordagem qualitativa, buscando entender os significados, motivações, valores e crenças $^{7}$ que envolvem a escolha da especialidade médica.

A pesquisa foi realizada no curso de Medicina da Universidade do Vale do Itajaí (Univali), que descreve em seu projeto pedagógico o perfil de um médico com formação geral, humanista, crítica e reflexiva, com capacidade para atuar na integralidade da atenção ${ }^{8}$.

A matriz curricular é organizada por meio de disciplinas, divididas em três ciclos: básico, clínico e internato médico. Ela possui disciplinas nas cinco grandes áreas descritas nas DCN de 20019: Clínica Médica, Clínica Cirúrgica, Ginecologia e Obstetrícia, Medicina de Família, e Comunidade e Pediatria ${ }^{8}$.

Para a amostra da pesquisa foram eleitos egressos do curso de Medicina dessa universidade, do período entre 2012 e 2015, que participaram de pelo menos três edições do Projeto Sérgio Arouca. Trata-se, portanto, de amostra intencional. As informações sobre os sujeitos foram fornecidas pela coordenação do curso de Medicina.

O Projeto Sérgio Arouca foi inspirado no Projeto Rondon, com o objetivo de propiciar ao aluno a vivência em cenários de grande carência social que representam a grande maioria da realidade nacional. O projeto busca integrar ações assistenciais e coletivas, além de promover a cidadania, tendo como lócus a atenção básica8 .

A amostra intencional se justifica quando os informantes podem responder melhor aos objetivos da pesquisa ${ }^{10}$. Neste caso, a intencionalidade buscou identificar como a exposição e a relativa identificação com a atenção básica influenciam a escolha da especialidade médica.

Por meio de roteiro semiestruturado, foram entrevistados inicialmente dez egressos, até o limite de 14 sujeitos, quando se deu a saturação de dados, justificando a interrupção da coleta de dados ${ }^{11}$.
Na análise dos dados foi utilizada a categoria Estilo de Pensamento (EP), de Ludwik Fleck, buscando identificar, com base nas falas dos entrevistados, os elementos que caracterizam a escolha da especialidade médica.

Estilo de Pensamento pode ser entendido como pressuposições com as quais um coletivo de pensamento constrói seu "edifício teórico"12, portanto, de cunho epistemológico. Fleck usa alguns elementos para caracterizar o EP. Nessa etapa da pesquisa, foram utilizados os elementos: protoideia; modo de ver ou perceber de forma dirigida; o agir de acordo; sistema de opiniões ${ }^{13}$.

Na teoria de Fleck, as experiências do presente estão ligadas às do passado, e aquelas se ligarão às do futuro - são as chamadas protoideias, esboços históricos evolutivos das teorias atuais que, apesar das variações dos EP, mantêm algumas concepções surgidas no passado ou partem delas para seu desenvolvimento, tendo, por conseguinte, grande valor heurístico ${ }^{13}$.

O EP tem como raiz uma disposição para ver ou perceber de forma dirigida, condicionada pelos pressupostos históricos, sociais e culturais de uma comunidade em determinada época ${ }^{13}$. Essa forma de ver gera uma disposição para um sentir seletivo e um agir de acordo ${ }^{12}$.

A construção do fato científico está intrinsecamente relacionada com essa forma de $\operatorname{ver}^{13}$. As teorias que embasam o modo de ver e o agir de acordo são chamadas de sistemas de opiniões e exercem "força sugestiva" sobre seus membros para determinado $\mathrm{EP}^{12}$.

Dessa forma, a caracterização desses elementos pertencentes ao EP permite entender o objeto investigado, neste caso, a escolha da especialidade médica, considerando tanto a motivação explícita quanto o contexto sócio-histórico-cultural que envolvem tais escolhas.

A etapa de análise foi realizada à semelhança de outros métodos qualitativos, com transcrição das entrevistas, leitura exaustiva do material, seleção de unidades de registro mais representativas das falas dos entrevistados, agregação dos dados e identificação com os elementos do EP (protoideia; modo de ver ou perceber de forma dirigida; o agir de acordo; sistema de opiniões) e, por fim, caracterização do EP.

O projeto foi submetido ao Comitê de Ética e Pesquisa e aprovado sob o Parecer $n^{\circ}$ 1.091.720, tendo sido respeitadas as diretrizes e normas da resolução CNS 466/2012.

\section{RESULTADOS E DISCUSSÃO}

Por meio da análise da fala dos entrevistados, foram identificados dois EP, conforme o Quadro 1. O mais prevalente, com 12 representantes, tem relação com o EP flexneriano, com 
tendência voltada à especialidade focal e ao mercado liberal, porém com características de abordagem ampliada dos problemas. De forma contra-hegemônica, em dois representantes foi identificado o EP da atenção básica, voltado ao sistema público universal.

\begin{tabular}{|c|c|c|}
\hline \multicolumn{3}{|c|}{$\begin{array}{c}\text { QUADRo } 1 \\
\text { Estilo de pensamento dos entrevistados, } \\
\text { segundo a escolha da especialidade }\end{array}$} \\
\hline Entrevistado & Especialidade escolhida & Estilo de pensamento \\
\hline 1 & $\begin{array}{l}\text { Medicina de Família e } \\
\text { Comunidade } \\
\text { Medicina de Família e } \\
\text { Comunidade }\end{array}$ & Atenção básica \\
\hline 3 & Clínica Médica & \\
\hline 4 & Pediatria & \\
\hline 5 & Ginecologia e Obstetrícia & \\
\hline 6 & Ginecologia e Obstetrícia & \\
\hline 7 & Medicina do Esporte & \\
\hline 8 & Psiquiatria & Flexneriano ampliado \\
\hline 9 & Psiquiatria & Flexneriano ampilado \\
\hline 10 & Cardiologia & \\
\hline 11 & Pneumologia & \\
\hline 12 & Mastologia & \\
\hline 13 & Ortopedia & \\
\hline 14 & Oftalmologia & \\
\hline
\end{tabular}

\section{Estilo de Pensamento Flexneriano Ampliado}

Dos 14 entrevistados, 12 apresentaram características de pertencimento a um EP que tem elementos do modelo flexneriano e biomédico e alguns pequenos elementos da atenção básica, os quais foram classificados como EP Flexneriano Ampliado.

O EP Flexneriano Ampliado tem como protoideia a explicação unicausal biológica do processo saúde-doença, desenvolvida a partir do descobrimento da bactéria por Pasteur no final do século XIX e que tipifica o rigor do raciocínio mecanicista e a correlação causa-efeito ${ }^{14}$. Essa forma de entender saúde começa a ser denominada "medicina científica".

No que se refere à formação, a protoideia desse EP tem suas raízes no Relatório Flexner, publicado em 1910, que propunha a reformulação do ensino médico com bases eminentemente biológicas, centrada objetivamente na doença de forma individual, tendo como lócus o hospital, o que resultava numa prática mecanicista ${ }^{2,15}$. A construção do relatório não foi isenta de intencionalidades, sendo financiada pela Rockfeller Foundation, que tinha grande interesse no desenvolvimento do complexo médico-industrial ${ }^{1}$. Esse modelo de educação médica ficou posteriormente conhecido como modelo flexneriano.
Atribui-se ao modelo flexneriano a ênfase nas especializações precoces, fragmentando o conhecimento e dificultando a visão integral ${ }^{16}$.

A publicação do Relatório Flexner marca a convergência de interesses entre o grande capital, a corporação médica e as universidades, com a institucionalização da "medicina científica"17. Dessa forma, esse relatório também pode ser considerado como protoideia do pensamento mercantil da medicina.

Essa união de interesses culminou no desenvolvimento de um modelo de atenção à saúde que veio a se tornar hegemônico no mundo e ficou conhecido como modelo biomédico.

A primeira característica de pertencimento a esse EP foi identificada pelo desejo ou escolha de uma especialidade médica focal. O modo de ver é representado pela necessidade expressa de ser especialista focal.

$$
\begin{aligned}
& \text { O especialista tem mais reconhecimento do que o clínico. } \\
& \text { (Entrevistado 4) } \\
& \text { A gente aprende na faculdade que ser bom médico é ser supe- } \\
& \text { respecialista. (Entrevistado } 8 \text { ) }
\end{aligned}
$$

A hegemonia do modelo biomédico nos serviços de saúde e suas características de fragmentação, mecanicismo, nosocentrismo e tecnicismo favorecem a visão para a superespecialização.

Nesse modelo, a especialização é justificada pela necessidade de melhor conhecimento das partes. Porém, isto leva à fragmentação e à divisão técnica do trabalho, objetivando os atos e relações dos profissionais de saúde, restritos a uma parte do corpo humano, sem compromisso com as necessidades integrais do ser humano ${ }^{18}$.

Tal forma de ver a prática médica leva à escolha de residências em especialidades focais, demonstrada por seus representantes, como mostra o Quadro 1. Nesse sentido, esse modo de ver se aproxima bastante de sua protoideia.

Essa tendência de valorização da especialidade em detrimento da prática generalista pode ser observada pela implantação do Programa de Valorização da Atenção Básica (Provab). A bonificação de $10 \%$ dada ao participante sobre a nota em programas de residência tem servido muito mais para o acesso a outras especialidades do que propriamente para a fixação de profissionais na atenção básica ${ }^{19}$.

Outra característica importante do EP é a abordagem dos problemas. Afastando-se um pouco da lógica biomédica, os entrevistados, apesar de optarem pela especialidade focal, demonstraram aspectos que os aproximam da visão ampliada dos problemas. 
Pra mim não é uma doença apenas. Eu procuro entender o contexto do paciente. E a Psiquiatria proporciona isso. (Entrevistado 9)

Você não precisa ser médico de família para fazer clínica ampliada. (Entrevistado 5)

Nas falas dos entrevistados surgiram aspectos relacionados aos pressupostos da saúde coletiva. Apesar das limitações que o trabalho do especialista pode apresentar quando comparado ao do médico generalista, as características relatadas podem ajudar o profissional a ser mais resolutivo, especialmente por entender melhor o problema e dar respostas que considerem o cuidado, superando a racionalidade anatomoclínica do modelo biomédico.

Esse modo de ver ampliado, mesmo a partir das especialidades focais, pode ser confirmado com um agir que considera o contexto e o cuidado:

A Pediatria precisa muito conversar com os pais, dar orientações. Muitas vezes, eles não têm noção porque nunca foram orientados. (Entrevistado 4 )

Uma gravidez planejada e outra que não foi planejada e é indesejada não podem ser conduzidas da mesma forma. (Entrevistado 5)

Um trabalho realizado numa universidade canadense após reforma curricular, passando de um currículo tradicional flexneriano para um currículo baseado na APS, demonstrou que, mesmo optando por especialidades, os médicos formados no currículo baseado na APS eram mais resolutivos do que os formados no currículo tradicional por agregarem à sua prática pressupostos da $\mathrm{APS}^{20}$, o que ratifica a importância da formação a partir da atenção básica.

Os representantes do EP Flexneriano, apesar de não optarem pela Medicina de Família e

Comunidade, optaram, em boa parte, por especialidades mais generalistas. Clínica Médica, Pediatria e Ginecologia e Obstetrícia em alguns países são especialidades consideradas básicas ${ }^{21}$, o que possibilita um olhar mais ampliado. Além disso, a Medicina do Esporte e a Psiquiatria, apesar de terem focos específicos, também apresentam características generalistas de olhar e abordagem.

Esta abordagem ampliada, ou mesmo a escolha de especialidades que permitem um olhar mais generalista, se afasta da protoideia flexneriana, podendo ser considerada uma variação do EP flexneriano clássico.

Essas aproximações e distanciamentos são denominados matizes de EP, nos quais existe uma variação do estilo, mantendo a ideia principal ${ }^{13}$.
Porém, apesar de demonstrarem a visão ampliada na abordagem dos problemas, a opção pela especialidade e a própria visão da profissão se relacionam principalmente à boa remuneração, aproximando os profissionais da protoideia flexneriana-biomédica:

Pode ter um conflito você querer ajudar as pessoas e receber por isso, mas é assim que o mundo está organizado, você depende de dinheiro. O problema é colocar o financeiro à frente de tudo. (Entrevistado 9)

Com certeza, o especialista ganha mais que o generalista. (Entrevistado 13)

Ainda que exista o desejo de ajudar as pessoas, as escolhas de profissão e especialidade apresentam um importante peso do componente financeiro, conferindo uma visão mercantilizada da profissão médica para este EP.

No Brasil, concomitantemente à criação do SUS e à proposta de universalização, as ideias de terceirização na gestão dos sistemas públicos e privatizações foram sendo incorporadas desde a década de 1990, favorecendo o pensamento mercantil da saúde em detrimento de uma visão de direitos sociais $^{22}$.

Esse cenário de contradições, historicamente, foi marcado pelo tensionamento do pensamento hegemônico neoliberal para o crescimento da mercantilização da saúde, vista, assim, como um bem econômico e espaço de circulação de capitall23, quadro que ainda persiste.

Essa visão liberal é ratificada pelo desejo expresso de inserção futura no mercado de trabalho. Apesar de citarem o trabalho no serviço público, ele é visto apenas como uma forma de complementação de renda, uma vez que o privado também tem limitações quanto ao retorno financeiro.

\footnotetext{
Eu me vejo trabalhando na minha clínica, tendo uma rotina tranquila, mas trabalhando no público também, porque eu acho que a gente precisa de ambos na questão financeira. Só o privado não se sustenta. (Entrevistado 3)
}

Essa tendência liberal da medicina também foi identificada em pesquisa com alunos do curso de Medicina do Centro Universitário de Anápolis, que demonstraram preferência em trabalhar futuramente no serviço privado, sendo que nenhum apresentou desejo de trabalhar exclusivamente no público ${ }^{24}$.

Em outra citação, um entrevistado, ao falar sobre o futuro profissional, aponta a preocupação com as pessoas em sua escolha: 
O meu sonho é ter meu consultório e atender como ginecologista na atenção básica. Minha avó sempre dizia para não esquecer o SUS e dedicar um tempo pra quem precisa e não pode pagar. (Entrevistado 5)

Apesar de destacar o trabalho no sistema público, aparece aqui a noção de Estado mínimo, em que o setor público é dedicado aos pobres e, desta forma, também ratifica o pensamento liberal no sentido de que quem tem poder de compra pode usufruir do privado.

Essa noção de estado mínimo também aparece quando os entrevistados falam da relação público-privado na saúde:

A grande maioria das pessoas, se pudesse, pagaria um plano. Os médicos também, na grande maioria, acham melhor trabalhar no privado, que tem mais recursos e permite crescimento. (Entrevistado 14)

A visão é de que o setor privado é melhor que o público, no que se refere tanto à qualidade quanto à possibilidade de crescimento profissional, o que pode explicar as preferências. Porém, o que chama a atenção é que todos os representantes desse EP relataram o desejo de dividir seu trabalho entre o privado e o público, sendo este último quase sempre como forma complementar de renda.

A proposta de universalização do SUS carrega características de um Estado de bem-estar social, inspirado na experiência europeia ${ }^{25}$. Porém, na prática, a configuração do Estado brasileiro com tendência neoliberal, aliada à falta de financiamento e interesse do setor privado, faz com que o público seja de baixa qualidade, voltado à população pobre.

Essa visão especialista liberal é sustentada por um sistema de opiniões que exerce força sugestiva sobre os membros do EP.

Existe a crença de que o especialista é mais competente que o generalista:

As especialidades de maior prestígio hoje são oftalmo e rádio. E o que a gente escuta, as de menor prestígio são Clínica Médica e Medicina de Família. (Entrevistado 13)

Essa crença foi se consolidando a partir da estruturação do modelo flexneriano-biomédico, que, ao longo dos anos, foi incorporando na atenção médica a dependência de tecnologias de alta densidade. Consequentemente, as especialidades médicas que passaram a ser mais valorizadas foram aquelas que conseguiram mais aporte de tecnologia dura em detrimento das tecnologias relacionais. Isso tem efeito sugestivo para a necessidade de fazer residência e, de preferência, em especialidades que agreguem alta tecnologia e alta remuneração.

A preferência por especialidades como Cirurgia, Oftalmologia, Dermatologia e Oncologia é guiada pelo maior prestígio social e alta remuneração que proporcionam, em detrimento de especialidades mais generalistas, como a Medicina de Família e Comunidade, e Pediatria, que apresentam menor remuneração e reputação social, portanto, dirigidas pelas ideias neoliberais ${ }^{26}$.

Essa valorização do especialista com consequente desvalorização do generalista, de certa forma, é legitimada pela própria população:

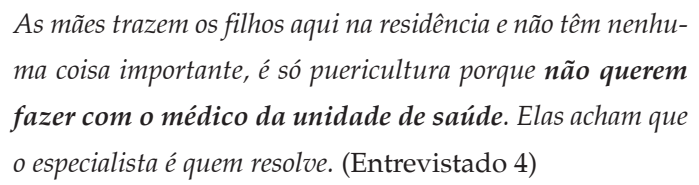

Esse pensamento de valorização do especialista foi historicamente construído com a própria estruturação dos serviços, com a lógica de que o pediatra atende a criança, o obstetra a gestante, e o cardiologista trata o coração. É a reprodução do pensamento cartesiano e das propostas de Flexner.

Além disso, a carga ideológica vinda da medicina especializada, com a utilização de alta densidade tecnológica, seduz a população e caracteriza a APS como medicina de baixa qualidade, repercutindo no plano político, em que os maiores investimentos são reservados à atenção especializada e hospitalar devido à visibilidade política ${ }^{27}$.

Porém, esse excesso de agregação tecnológica trouxe complicações ao modelo biomédico, especialmente no que tange à relação médico-paciente e à personalização na atenção:

$$
\begin{aligned}
& \text { A relação médico-paciente não era valorizada. A humaniza- } \\
& \text { ção, acolhimento, clínica ampliada são coisas que surgiram } \\
& \text { de um tempo pra cá e devem fazer parte da prática médica de } \\
& \text { qualquer especialidade hoje. (Entrevistado 5) }
\end{aligned}
$$

As novas teorias e novos fatos que vão surgindo são absorvidos pelos Coletivos de Pensamento, reinterpretados e adaptados à sua forma de ver ${ }^{13}$. Esse grupo de entrevistados, diante de suas complicações quanto à humanização e abordagem dos problemas, se apropriou desses fatos, adaptando-os à sua visão (especialista focal).

Essa incorporação de conceitos e práticas da saúde coletiva introduz um novo sistema de opiniões no EP flexneriano. Por isso, pode ser considerado como matiz do EP, razão pela qual o denominamos ampliado. 
Já a fundamentação do caráter liberal da profissão é sustentada pela própria estruturação de estado mínimo:

Nós precisamos de uma saúde pública forte, mas também de uma medicina privada ou convênio, que desonera o próprio SUS, para aqueles $30 \%$ que podem pagar. (Entrevistado 11)

Ainda que se pense numa saúde pública forte, a convivência com o privado sempre vai gerar um tensionamento do capital para que o público seja de baixa qualidade, favorecendo a compra de serviços por aqueles que podem pagar.

Na lógica neoliberal de Estado mínimo, os programas ou políticas governamentais têm apenas caráter compensatório para a população mais pobre, abrindo espaço para as iniciativas neoliberais ${ }^{28}$.

\section{Estilo de Pensamento da Atenção Básica}

Dos 14 entrevistados, apenas dois foram identificados como pertencentes ao EP da atenção básica. Esse EP tem como protoideia as propostas discutidas e sistematizadas em Alma-Ata, em 1978, na I Conferência Internacional de Cuidados Primários à Saúde, cuja centralidade apontava a saúde como direito humano fundamental ${ }^{29}$.

O documento final da conferência afirmava que as iniquidades em saúde eram a expressão das desigualdades econômicas e sociais, e que seriam necessárias ações intersetoriais, criação de sistemas nacionais de saúde com base comunitária e efetiva participação social nesse processo $^{29}$.

A sistematização desse modelo foi, posteriormente, denominada Atenção Primária à Saúde.

Concomitantemente a esse movimento mundial, na década de 1970, inicia-se o Movimento da Reforma Sanitária Brasileira, que se opunha à ditadura militar e ao modelo de saúde curativista e não inclusivo adotado pelo governo, discutindo novas possibilidades de práticas de saúde que se aproximavam do conceito de APS de Alma-Ata ${ }^{30}$.

A APS no Brasil se concretiza enquanto política em 1994, ainda como proposta seletiva, sob a denominação de Programa Saúde de Família, e posteriormente foi ampliada como política estruturante de todo o sistema de saúde, então chamada de Atenção Básica ${ }^{31}$. Essas propostas dão materialidade à construção de um novo EP, ganhando direcionalidade com a publicação das DCN dos cursos de Medicina em 2001, cujo ideário representa sua protoideia no que se refere à educação médica para a formação generalista e integral ${ }^{9}$.

A identificação com essas ideias foi caracterizada nas falas dos entrevistados 1 e 2, que apresentam uma visão generalista e ampliada do processo saúde-doença:
A grande maioria dos problemas tem uma causa social, ambiental, emocional, que no final se reflete no corpo físico. (Entrevistado 1)

Essa primeira fala remete ao sentido primário de integralidade, cuja explicação do processo saúde-doença parte da determinação social, do condicionante ecológico-ambiental e do desencadeador biológico ${ }^{32}$.

Outro sentido da integralidade que caracterizou esse modo de ver tem relação com a clínica ampliada:

O bom médico não é aquele que conhece todos os protocolos, mas que vai além da doença e tenta entender o contexto da pessoa que tem o problema. (Entrevistado 2)

A clínica ampliada pressupõe a consideração da singularidade e do contexto que envolve o problema e que, portanto, se distingue de todos os outros e não pode ser entendido como mera formalidade protocolar ${ }^{33}$.

A visão ampliada e o exercício desta, na visão dos dois entrevistados, são possíveis no lócus da atenção básica:

O conhecimento do território, das famílias, das pessoas éfundamental para que a gente possa responder às necessidades individuais e coletivas. (Entrevistado 2)

Ainda que outras especialidades permitam uma visão ampliada do processo saúde-doença, a atenção básica propicia, de fato, conhecer o contexto, pela adscrição de território e longitudinalidade do cuidado. Consequentemente, as respostas são mais efetivas.

Além disso, esse modo de ver ampliado é confirmado pelo agir de acordo:

\footnotetext{
$\mathrm{Na}$ atenção básica, conhecendo a comunidade e as pessoas, você consegue fazer uma clínica muito melhor, consegue fazer grupos, visitas. (Entrevistado 1)

E consegue pensar no cuidado, na prevenção, na promoção de saúde, e, é claro, ter uma boa clínica. (Entrevistado 2)
}

As falas acima remetem à orientação do processo de trabalho da atenção básica, que, entre as atribuições dos profissionais de saúde, inclui visita domiciliar, realização de atividades coletivas e consultas ${ }^{34}$.

A prática da integralidade também pode ser identificada na menção sobre as ações integradas de saúde, considerando a promoção, prevenção e recuperação ${ }^{32}$. 
Outra característica deste EP identificada nos entrevistados é a visão da medicina como forma de ajudar as pessoas:

Eu até brinco que eu escolhi medicina de família porque eu gosto mais dos pacientes do que de qualquer parte deles. Você pode ouvir, conversar, aconselhar e ajudar as pessoas. (Entrevistado 2)

Ainda que a procura pela especialidade de MFC seja pequena no Brasil, um estudo com alunos de Medicina revelou que a possibilidade de trabalhar com um vasto rol de problemas e prática clínica integral, aliada à importância social da especialidade, são aspectos que influenciam positivamente a escolha da especialidade ${ }^{24}$.

A importância dada aos aspectos sociais pode ser confirmada com o modo de ver a organização do setor saúde:

Eu acho que tem que ser público pra todos e com qualidade, porque o privado sempre vai ter aquela coisa de pedir coisas desnecessárias, de ser mediada pelo lucro. (Entrevistado 1)

Contrariando a visão hegemônica de mercantilização da saúde, o modo de ver é de um serviço público universal e de qualidade, exaltando os malefícios que o interesse mercantil pode causar às pessoas.

O crescimento do setor privado na saúde e a consequente mercantilização têm causado, em diversos países, iniquidades em saúde, especialmente em razão das grandes desigualdades sociais existentes ${ }^{35}$.

Condizentes com a visão universalista da saúde como expressão do direito, os representantes deste EP relatam o desejo de trabalhar eminentemente no serviço público, o agir de acordo:

No futuro, eu quero trabalhar numa cidadezinha, numa equipe que compreenda o que é ESF e com uma gestão que preze a qualidade e não a quantidade. (Entrevistado 2)

Além do desejo de trabalhar futuramente no serviço público, outro ponto relevante presente na fala diz respeito à qualidade. Além de se tratar de uma questão bioética indiscutível, a qualidade do serviço público é fundamental para a consolidação do SUS enquanto política pública universal e, ainda, como resposta às necessidades de saúde da população ${ }^{36}$.

Esse modo de ver da atenção básica é sustentado por um sistema de opiniões que apresenta a APS como eixo estruturante de um sistema de saúde público e universal, como expressão do direito humano.
Um primeiro aspecto que tem força sugestiva nos membros do EP diz respeito à resolubilidade da atenção básica:

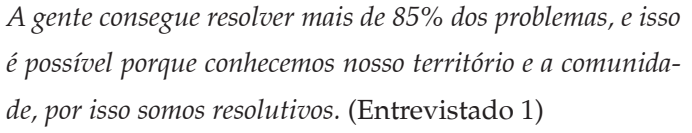

Existe a crença de que o trabalho na atenção básica tem vantagens em relação a outras formas de organização do processo de trabalho. Essa convicção de resolubilidade graças ao reconhecimento do processo de trabalho exerce força sugestiva dentro do EP e é sustentada por diversos estudos.

A APS, reconhecidamente, é a estratégia estruturante que obteve melhor impacto positivo nos indicadores de saúde de países com sistemas de saúde universais, apresentando maior eficiência no fluxo dos usuários no sistema, cuidado mais efetivo de condições crônicas, maior utilização de práticas preventivas, maior satisfação dos usuários e diminuição das iniquidades no acesso aos serviços e estado geral de saúde ${ }^{37}$.

Outro aspecto que exerce força sugestiva e que compõe o sistema de opiniões do EP da atenção básica se refere ao caráter da medicina:

Tem gente que acha que a gente se priva de status e dinhei-
ro. Isso depende dos teus valores. Eu ganho valorização
da comunidade e gratidão das pessoas, o que é impagável.
(Entrevistado 1)

O que sustenta esse modo de ver é a percepção de que ajudar as pessoas está acima da necessidade de obter boa remuneração, posição oposta ao modo de ver flexneriano, que também cita a ajuda às pessoas, porém as escolhas iniciais sempre recaem sobre o financeiro.

Nesse sentido, a Medicina de Família e Comunidade no Brasil é uma vertente da medicina cuja atividade cotidiana possibilita a agregação de valor ao seu trabalho abstrato ${ }^{38}$. Ela representa uma prática profissional ideológica contra-hegemônica, cujo valor agregado se concentra principalmente no propósito de ajudar as pessoas, em contraposição ao pensamento mercantil da medicina.

E, por fim, o sistema de opiniões deste EP parte do princípio de que saúde é direito de todos e dever do Estado.

Todo mundo tem direito, está na Constituição. Pra mim é inconcebível pagar pela saúde. Saúde é como poder respirar e andar na rua, é como escola que tem que ser pública pra todos, não pode ser só pra quem pode pagar. (Entrevistado 2)

$96 \mid$\begin{tabular}{l|l} 
REVISTA BRASILEIRA DE EDUCAÇÃO MÉDICA \\
$42(2): 88$ - $99 ; 2018$
\end{tabular} 
A sustentação do EP é baseada nas premissas de um Estado de bem-estar social, com políticas sociais amplas e universais, superando a visão de Estado mínimo, de atenção de baixa qualidade para a população pobre.

Essa lógica, em teoria, é garantida pela Constituição Federal de 1988, que inaugura um modelo de proteção social que inclui a previdência, a saúde e a assistência como parte da seguridade social, introduzindo a noção de direitos sociais universais como parte da condição de cidadania ${ }^{39}$.

\section{CONSIDERAÇÕES FINAIS}

Mesmo com a exposição e identificação com a atenção básica no processo de graduação, a hegemonia do EP flexneriano na escolha da especialidade médica se fez presente, com tendência para a especialidade focal e para o sistema liberal privado.

De forma contra-hegemônica, aparece o EP da atenção básica, que tem como eixo a Medicina de Família e Comunidade, de caráter eminentemente público.

Porém, a aproximação com o EP da atenção básica propicia o aparecimento de um matiz do EP flexneriano clássico no que se refere à abordagem do problema, que pode favorecer uma prática mais ampliada e humanizada.

Para esse grupo de entrevistados, a aproximação com a atenção básica na graduação parece ter sido importante em sua formação, mas também sugere que as mudanças na graduação, isoladamente, parecem não ter força suficiente para consolidar o objetivo do preceito legal de ordenamento do SUS na formação de recursos humanos, especialmente quanto ao seu provimento.

Os resultados desta pesquisa, ainda que não possam ser generalizados, sugerem que, além das políticas de formação, talvez seja necessário repensar as políticas de provimento médico para a atenção básica, uma vez que a consolidação do SUS como política ampla de saúde, que garanta atenção universal e integral, depende tanto da qualidade quanto da quantidade suficiente de profissionais.

Nesse sentido, a ampliação da oferta do número de vagas de graduação para o curso de Medicina e a universalização do acesso às residências médicas com priorização para os Programas de Medicina de Família e Comunidade, previstas no Programa Mais Médicos ${ }^{6}$, são determinações que fazem valer o papel do Estado na regulação da formação para atendimento das necessidades do setor, ainda que não possam ser garantidas quanto à sua efetividade no provimento de profissionais.

Por outro lado, soluções relacionadas a infraestrutura adequada, desprecarização das relações de trabalho, financiamento suficiente e estabelecimento de plano de carreira e remuneração ${ }^{27}$ também devem ser discutidas e equacionadas, pois essas questões, na opinião dos entrevistados, parecem dificultar a escolha da atenção básica enquanto campo profissional do médico.

Toda essa atmosfera tem gerado grande tensionamento, que pode ser explicado pelos diferentes estilos de pensamento, que carregam consigo sua carga político-ideológica.

\section{REFERÊNCIAS}

1. Veiga MV. Elementos para a mudança curricular no curso de Medicina de uma universidade no sul do Brasil. Itajaí; 2015.Mestrado [Dissertação]- UNIVALI.

2. Maranhão EA, Gomes AP, Siqueira-Batista R. O que mudou na Educação Médica a partir das Diretrizes Curriculares Nacionais: sob os olhares do Jano de duas faces. In: Streit DS, Barbosa Neto F, Lampert JB, Lemos JMC, Batista N (orgs). Educação Médica: 10 anos de Diretrizes Curriculares Nacionais. Rio De Janeiro: Associação Brasileira de Educação Médica, 2012.

3. Paim JS. Reforma sanitária brasileira: contribuição para a compreensão e crítica. Salvador: EDUFBA; Rio de Janeiro: FIOCRUZ, 2008.

4. Brasil. Constituição da República Federativa do Brasil. Brasília: Senado Federal, 1988.

5. Alves CRL, Belisário AS, Lemos JMC, Abreu DMX, D’avila LS, Goulart LMHF. Mudanças Curriculares: principais dificuldades na implementação do PROMED. Rev. bras. educ. med. 2013; 37(2)157-166.

6. Brasil. Lei n. 12.871, de 22 de outubro de 2013. Institui o Programa Mais Médicos. Presidência da República. Casa Civil. Diário Oficinal da União - Brasília, 2013.

7. Minayo MCS. O desafio do conhecimento: pesquisa qualitativa em saúde. 14 ed. São Paulo: Hucitec, 2014.

8. UNIVALI. Projeto Pedagógico do curso de Medicina da UNIVALI. Centro de Ciências da Saúde. Itajaí, 2015.

9. Brasil. Ministério da Educação. Conselho Nacional de Educação. Câmara de Educação Superior, 2001. Diretrizes Curriculares Nacionais do Curso deGraduação em Medicina. Homologada em 03/10/2001, Parecer CES 1.133/2001, Resolução CNE/CES № 4, de 7/11/2001. Brasília: Ministério da Educação, 2001.

10. Canzonieri AM. Metodologia da Pesquisa Qualitativa na Saúde. 2ª ed. Petrópolis: Vozes, 2011.

11. Minayo MCS. Amostragem e saturação em pesquisa qualitativa: consensos e controvérsias. Revista Pesquisa Qualitativa $2017 ; 5(7) 1-12$.

12. Schafer L, Schnelle T. Fundamentação da perspectiva sociológica de LudwikFleck na teoria da ciência. In: Fleck L. Gênese e desenvolvimento de um fato científico. Tradução: 
Georg Otte e Marina Camilo de Oliveira. Belo Horizonte: Fabrefactum; 2010. p. 1-36.

13. Fleck L. Gênese e desenvolvimento de um fato científico. Tradução: Georg Otte e Marina Camilo de Oliveira. Belo Horizonte: Fabrefactum, 2010.

14. Barros JAC. Pensando o processo saúde doença: a que responde o Modelo Biomédico? Saúde soc. 2012; 11(1)67-84.

15. Ferreira JR, Campos FE. Reformulando a Educação Médica no Brasil: o importante papel das Diretrizes Curriculares Nacionais. In: Streit DS, Barbosa Neto F, Lampert JB, Lemos JMC, Batista N (orgs). Educação Médica: 10 anos de Diretrizes Curriculares Nacionais. Rio De Janeiro: Associação Brasileira de Educação Médica, 2012.

16. Nóbrega-Therrien SM, Souza PMM, Pinheiro FMC, Castro VS. Formação para a Estratégia Saúde da Família na graduação em Medicina. Rev. bras. educ. med. 2015; 39(1)112-118.

17. Mendes EV. A Evolução Histórica da Prática Médica, Suas Implicações no Ensino, na Pesquisa e na Tecnologia Médica. Belo Horizonte: PUC/FINEP, 1985.

18. Gomes RS, Pinheiro R, Guizardi FL. A orquestração do trabalho em saúde: um debate sobre a fragmentação das equipes. In. Pinheiro R, Müller Neto JS, Ticianel FA, Spinelli MAS, Silva Junior AG. Construção social da demanda por cuidado: revisitando o direito à saúde, o trabalho em equipe, os espaços públicos e a participação. Rio de Janeiro: CEPESC/IMS/UERJ/ABRASCO, 2013. p.173-185.

19. Feuerwerker LCM. Médicos para o SUS: gestão do trabalho e da educação na saúde no olho do furacão! Interface (Botucatu) 2013; 17(47)929-930.

20. Tamblyn R, Abrahamowicz M, Dauphinee D, Girard N, Barlett G, Grand'Maison P, Brailovsky C. Effect of a community oriented problem based learning curriculum on quality of primary care delivered by graduates: historical cohort comparison study. BMJ, 2005; 331: 1002.

21. Scheffer M. Demografia médica no Brasil 2015. São Paulo: Departamento de Medicina Preventiva da Faculdade de Medicina da USP; Conselho Regional de Medicina do Estado de São Paulo; Conselho Federal de Medicina, 2015.

22. Almeida C. Parcerias público-privadas (PPP) no setorsaúde: processos globais e dinâmicas. Cad. Saúde Pública 2017; 33(Sup2)e00197316.

23. Gadelha CAG, Braga, PSC. Saúde e inovação: dinâmica econômica e Estado de Bem-Estar Social no Brasil. Cad. Saúde Pública 2016; 32(Sup2)e00150115.

24. Issa AHTM. Percepções discentes sobre a Estratégia de Saúde da Família e a escolha pela especialidade de Medicina de Família e Comunidade. Goiânia; 2013. Mestrado
[Dissertação] - Universidade Federal de Goiás, Faculdade de Medicina.

25. Ocké-Reis CO. SUS: o desafio de ser único. Rio de Janeiro: Editora FIOCRUZ, 2012.

26. Costa JRB, Romano VF, Costa RR, Gomes AP, Alves LA, Siqueira-Batista R. A transformação curricular e a escolha da especialidade médica. Rev. bras. educ. med. 2014; 38(1)47-58.

27. Mendes EV. O cuidado das condições crônicas na atenção primária à saúde: o imperativo da consolidação da estratégia da saúde da família. Brasília: Organização Pan-Americana da Saúde, 2012.

28. Sousa AMC.Universalidade da saúde no Brasil e as contradições da sua negação como direito de todos. R. Katál 2014; 17(2)227-234.

29. Organização Mundial da Saúde. Declaração de Alma-Ata. Alma-Ata: Organização Mundial da Saúde,1978.

30. Pereira IC, Oliveira MAC. Atenção primária, promoção da saúde e o Sistema Único de Saúde: um diálogo necessário. São Paulo: Escola de Enfermagem da Universidade de São Paulo, 2014.

31. Instituto Sul-Americano de Governo em Saúde. Mapeamento e Análise dos Modelos de Atenção Primária à Saúde nos Países da América do Sul - Atenção Primária à Saúde no Brasil. Rio de Janeiro: Instituto Sul-Americano de Governo em Saúde, 2014.

32. Maeyama MA, Jasper CH, Nilson, LG, Dolny LL, Cutolo LRA. Promoção da Saúde como tecnologia para transformação social. RBTS 2015; 2(2)129-143.

33. Campos GWS, Cunha GT, Figueiredo MD. Práxis e formação paidéia: apoio e co-gestão em saúde. São Paulo: Hucitec, 2013.

34. Brasil. Ministério da Saúde. Secretaria de Atenção à Saúde. Departamento de Atenção Básica. Política Nacional de Atenção Básica. Brasília: Ministério da Saúde, 2012.

35. Mclntyre D, Mooney G. (orgs). Aspectos Econômicos da Equidade em Saúde. Rio de Janeiro: Editora Fiocruz, 2014.

36. Brasil. Ministério da Saúde. Portaria GM/MS nº 1.654, de 19 de julho de 2011. Institui no âmbito do Sistema Único de Saúde, o Programa Nacional de Melhoria do Acesso e da Qualidade da Atenção Básica (PMAQ-AB) e o Incentivo Financeiro do PMAQ-AB, denominado Componente de Qualidade do Piso de Atenção Básica Variável- PAB variável. Diário Oficial da União - Brasília, 2011.

37. Starfield B. Atenção primária: equilíbrio entre as necessidades de saúde, serviços e tecnologia. Brasília: UNESCO, 2002.

38. Testa M. Pensar em Saúde. Porto Alegre: Artes Médicas, 1992. 
39. Fleury S. The Welfare State in Latin America: reform, innovation and fatigue. Cad. Saúde Pública 2017; 33(Sup 2): e00058116.

\section{CONTRIBUIÇÃO DOS AUTORES}

Todos os autores participaram da concepção e desenho do estudo, da análise e interpretação dos dados, bem como da redação e revisão final deste texto.

\section{CONFLITO DE INTERESSES}

Os autores declaram não haver conflito de interesses de ordem pessoal, comercial, acadêmica, política ou financeira na produção do manuscrito.

\section{ENDEREÇO PARA CORRESPONDÊNCIA}

Marcos Aurélio Maeyama

Rua Uruguai, 458

Centro - Itajaí

CEP 88302-901 - SC

E-mail: marcos.aurelio@univali.br unrestricted use, distribution, and reproduction in any medium, provided the original work is properly cited. 